\title{
Leptin resistance contributes to obesity and hypertension in mouse models of Bardet-Biedl syndrome
}

\author{
Kamal Rahmouni, ${ }^{1}$ Melissa A. Fath, ${ }^{2}$ Seongjin Seo, ${ }^{2,3}$ Daniel R. Thedens, ${ }^{4}$ \\ Christopher J. Berry, ${ }^{1}$ Robert Weiss, ${ }^{1}$ Darryl Y. Nishimura, ${ }^{2}$ and Val C. Sheffield ${ }^{2,3}$ \\ ${ }^{1}$ Department of Internal Medicine, ${ }^{2}$ Department of Pediatrics, ${ }^{3}$ Howard Hughes Medical Institute, and \\ ${ }^{4}$ Department of Radiology, University of lowa Carver College of Medicine, Iowa City, lowa, USA
}

\begin{abstract}
Bardet-Biedl syndrome (BBS) is a heterogeneous genetic disorder characterized by many features, including obesity and cardiovascular disease. We previously developed knockout mouse models of 3 BBS genes: $B B S 2, B B S 4$, and BBS6. To dissect the mechanisms involved in the metabolic disorders associated with $B B S$, we assessed the development of obesity in these mouse models and found that $B B S$-null mice were hyperphagic, had low locomotor activity, and had elevated circulating levels of the hormone leptin. The effect of exogenous leptin on body weight and food intake was attenuated in BBS mice, which suggests that leptin resistance may contribute to hyperleptinemia. In other mouse models of obesity, leptin resistance may be selective rather than systemic; although mice became resistant to leptin's anorectic effects, the ability to increase renal sympathetic nerve activity (SNA) was preserved. Although all 3 of the BBS mouse models were similarly resistant to leptin, the sensitivity of renal SNA to leptin was maintained in $\mathrm{Bbs} 4^{-/-}$and $\mathrm{Bbs6^{-/- }}$ mice, but not in $\mathrm{Bbs2} 2^{-/-}$mice. Consequently, $\mathrm{Bbs}^{-/-}$and $\mathrm{Bbs} 6^{-/-}$mice had higher baseline renal SNA and arterial pressure and a greater reduction in arterial pressure in response to ganglionic blockade. Furthermore, we found that BBS mice had a decreased hypothalamic expression of proopiomelanocortin, which suggests that BBS genes play an important role in maintaining leptin sensitivity in proopiomelanocortin neurons.
\end{abstract}

\section{Introduction}

Bardet-Biedl syndrome (BBS) is a pleiotropic autosomal recessive disorder with the primary clinical features of obesity, retinopathy, polydactyly, learning disabilities, and hypogenitalism $(1,2)$. BBS is also associated with an increased susceptibility to hypertension and cardiovascular disorders $(1,3,4)$. Although BBS is rare in the general population, there has been considerable interest in identifying the genes and determining the pathological mechanisms involved in BBS because some components of the phenotype are very common in the general population. Also, a recent study showed that polymorphisms in certain BBS genes might increase the risk of obesity and hypertension in non-BBS individuals (5).

BBS is genetically heterogeneous, and 12 BBS genes have been identified to date (6-17). Much evidence suggests that BBS genes play a role in cilia function and/or maintenance $(18,19)$. Most BBS genes are expressed in ciliated organisms and not in nonciliated organisms (20). Many of the BBS proteins have been shown to localize to basal bodies, which are modified centrioles found at the base of cilia and flagella (19). We developed 3 different BBS-knockout mouse models

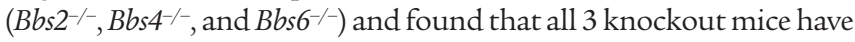
defects in flagella formation during spermatogenesis, although these animals do develop other motile and primary cilia (21-23). Although $B b s 6^{-/-}$animals are able to form cilia, sensory neuronal cilia of the cochlea and olfactory bulb are abnormal (24).

Nonstandard abbreviations used: AgRP, agouti-related protein; BAT, brown adipose tissue; BBS, Bardet-Biedl syndrome; CSF, cerebrospinal fluid; HR, heart rate; MAP, mean arterial pressure; NPY, neuropeptide Y; POMC, proopiomelanocortin; SNA, sympathetic nerve activity.

Conflict of interest: The authors have declared that no conflict of interest exists. Citation for this article: J. Clin. Invest. 118:1458-1467 (2008). doi:10.1172/JCI32357.
Obesity is a central feature of BBS, but the pathophysiological pathways leading to excessive body fat in this syndrome remain largely unknown. Obesity results from energy imbalance between ingested and expended calories. Energy balance is largely regulated by the central nervous system, which senses metabolic status from a wide range of hormonal and neural signals (25). Several brain regions ranging from the cortex to the brainstem are known to be involved in energy homeostasis, with the hypothalamus playing a key role. The identification of leptin has helped unravel the architecture of neuroendocrine circuitry that controls appetite and energy homeostasis. This hormone is expressed mainly by adipocytes and is released in the blood in proportion to the amount of adipose tissue (26). The severe obesity and the hyperphagia caused by the absence of leptin or its receptor in rodents and humans indicate the importance of this hormone for the control of energy homeostasis.

In lean subjects, leptin circulates at low levels $(5-15 \mathrm{ng} / \mathrm{ml})$. Plasma leptin is transported to the central nervous system by a saturable, unidirectional system (27) that involves binding of leptin to the short form of the leptin receptor located at the endothelium of the vasculature and the epithelium of the choroid plexus (28). Leptin suppresses appetite and increases energy expenditure by activating leptin receptors on specific neurons. At least 2 classes of neuronal pathways are known to account for leptin sensitivity within the arcuate nucleus of the hypothalamus (29): (a) a catabolic pathway, which is represented essentially by the proopiomelanocortin (POMC) neurons and is activated by leptin, and (b) an anabolic pathway, which is represented principally by neuropeptide Y (NPY) neurons (which also express agouti-related protein [AgRP]) and is inhibited by leptin. In POMC neurons, leptin is known to increase the gene expression of the Pomc gene. In contrast, leptin inhibits the expression of the Npy and Agrp genes in NPY neurons. 

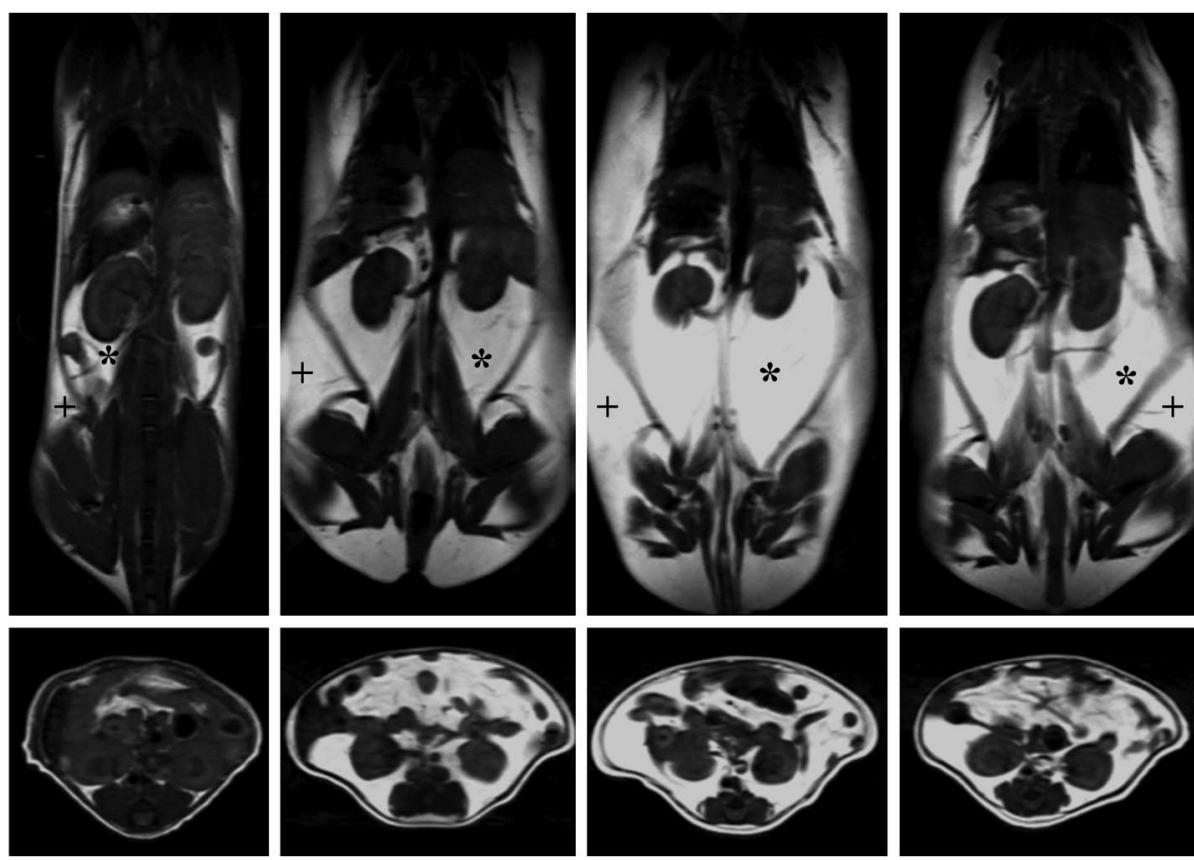

Bbs2- $^{-1}$

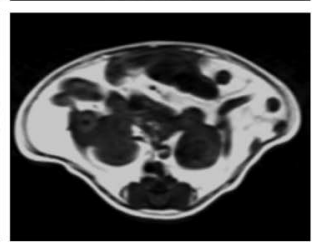

Bbs4 ${ }^{-/}$

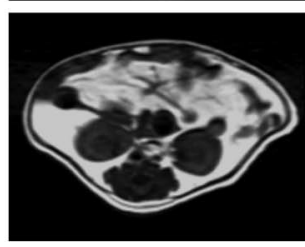

Bbs6 $^{-1}$
Figure 1

Representative T1-weighted MRI demonstrating greater fat mass in $\mathrm{Bbs}^{-/-}$, $\mathrm{Bbs4}^{-/-}$, and $\mathrm{Bbs6}^{-/-}$mice than in wildtype littermate controls. Coronal (top) and axial abdominal (bottom) sections of wild-type and BBS mice are shown. With this pulse-sequence, fat appears white and muscle and water appear gray or black. The plus signs indicate subcutaneous fat, and the asterisks indicate visceral fat.
Other effects of leptin, besides the modulation of energy homeostasis, include activation of the sympathetic nervous system and an increase in arterial pressure (30). Interestingly, in several mouse models of obesity, the ability of leptin to increase cardiovascular sympathetic nerve activity (SNA) is preserved, despite resistance to leptin's effect on food intake, body weight, and thermogenic sympathetic tone $(31,32)$.

Here, we sought to use mouse models to further explore and dissect the mechanisms involved in the metabolic and cardiovascular disorders associated with BBS. We hypothesize that defects in energy balance and central neurogenic mechanisms play a major pathophysiological role in obesity and in hypertension associated with the deletion of $B b s$ genes in mice. The pivotal role of leptin in energy homeostasis led us to assess potential alterations in the action of this hormone on energy homeostasis and sympathetic and cardiovascular function.

\section{Results}

Obesity in BBS-knockout mice. We created mutant models of 3 of the

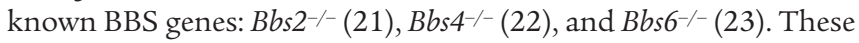
knockout mice share many features, a number of which are observed in human BBS patients, including obesity. Indeed, deletion of any of the 3 BBS genes leads to increases in body weight and fat mass (Figure 1 and Table 1) and is associated with hyperphagia, decreased locomotor activity, and high circulating levels of leptin (Table 1). To test whether the hyperleptinemia associated with BBS mice occurs early in life, we measured plasma leptin levels in 3 groups of

\section{Table 1}

5-6-week-old mice with no significant difference in body weight: wild-type $(14 \pm 1 \mathrm{~g} ; n=4), B b s 2^{-/-}(15 \pm 1 \mathrm{~g} ; n=3)$, and $B b s 4^{-/-}(12 \pm 2 \mathrm{~g}$; $n=3)$. We found that plasma leptin levels were elevated 3.1- and 2.3-fold, respectively, in $\mathrm{Bbs} 2^{-/-}$and $\mathrm{Bbs} 4^{4^{--}}$mice.

To assess the relative contributions of hyperphagia and decreased energy expenditure to the obesity associated with deletion of the BBS genes, we performed a pair-feeding experiment in which 5- to 7-week-old $B b s 2^{-/-}$and $B b s 4^{-/-}$mice were given the same amount of food consumed by their wild-type littermate controls for 13 weeks. Despite pair-feeding, both $\mathrm{Bbs} 2^{2^{--}}$and $\mathrm{Bbs} 4^{-{ }^{-}}$mice continued to have increased adiposity (2-3-fold higher visceral adipose tissue: reproductive, omental, and perirenal fat depots) compared with controls (Table 2). Taken together, these results indicate that BBS mice have low energy expenditure, which may contribute to obesity in these animals.

Exogenous systemic leptin failed to alter body weight and appetite in BBSknockout mice. The increased circulating level of leptin in BBS-knockout mice prompted us to investigate the role of leptin in the obesity associated with these animal models. To test whether BBS-knockout mice have an altered sensitivity to leptin, we compared the effect of

Characteristics of wild-type control and BBS mice

\begin{tabular}{|c|c|c|c|c|}
\hline Parameter & Wild-type & Bbs2-- & Bbs4-/- & $\mathrm{Bbs6}^{-/-}$ \\
\hline Body weight (g) & $28.7 \pm 0.7$ & $40.6 \pm 2.4^{A}$ & $41.1 \pm 2.1^{A}$ & $40.3 \pm 1.9^{A}$ \\
\hline Food intake (g) & $3.65 \pm 0.05$ & $4.73 \pm 0.24 \mathrm{~A}$ & $4.46 \pm 0.12^{\mathrm{A}}$ & $4.28 \pm 0.11^{A}$ \\
\hline Locomotor activity (AU) & $66.8 \pm 2.8$ & $35.2 \pm 5.6^{A}$ & $35.1 \pm 1.6^{A}$ & $37.4 \pm 1.5^{A}$ \\
\hline BAT (g) & $0.09 \pm 0.01$ & $0.29 \pm 0.05^{\mathrm{A}}$ & $0.30 \pm 0.04^{A}$ & $0.28 \pm 0.04^{A}$ \\
\hline Reproductive fat (g) & $0.59 \pm 0.07$ & $3.24 \pm 0.59^{A}$ & $3.01 \pm 0.39^{A}$ & $2.35 \pm 0.34^{\mathrm{A}}$ \\
\hline Omental fat $(g)$ & $0.22 \pm 0.04$ & $1.81 \pm 0.28^{A}$ & $1.39 \pm 0.30^{A}$ & $1.42 \pm 0.17^{\mathrm{A}}$ \\
\hline Perirenal fat $(\mathrm{g})$ & $0.18 \pm 0.02$ & $1.25 \pm 0.26^{\mathrm{A}}$ & $1.00 \pm 0.16^{A}$ & $0.88 \pm 0.16^{A}$ \\
\hline Plasma leptin (ng/ml) & $4.1 \pm 1.5$ & $50.5 \pm 17.0^{\mathrm{A}}$ & $43.2 \pm 10.0^{\mathrm{A}}$ & $43.5 \pm 10.0^{\mathrm{A}}$ \\
\hline
\end{tabular}

Data are mean \pm SEM; $n=7-43$ mice per group. ${ }^{A} P<0.05$ compared with wild-type controls. 
Table 2

Effect of pair-feeding on body weight and fat depots in BBS mice

\begin{tabular}{llll} 
Parameter & Wild-type & \multicolumn{1}{c}{ Bbs2 $^{-/}$} & Bbs $^{-/-}$ \\
Body weight $(\mathrm{g})$ & $24.3 \pm 1.5$ & $27.1 \pm 3.2$ & $24.7 \pm 3.0$ \\
BAT $(\mathrm{g})$ & $0.13 \pm 0.03$ & $0.18 \pm 0.06^{\mathrm{A}}$ & $0.17 \pm 0.03^{\mathrm{A}}$ \\
Reproductive fat $(\mathrm{g})$ & $0.42 \pm 0.09$ & $0.97 \pm 0.39^{\mathrm{A}}$ & $1.00 \pm 0.50^{\mathrm{A}}$ \\
Omental fat $(\mathrm{g})$ & $0.27 \pm 0.04$ & $0.65 \pm 0.19^{\mathrm{A}}$ & $0.52 \pm 0.15^{\mathrm{A}}$ \\
Perirenal fat $(\mathrm{g})$ & $0.24 \pm 0.07$ & $0.49 \pm 0.10^{\mathrm{A}}$ & $0.42 \pm 0.15^{\mathrm{A}}$ \\
\hline
\end{tabular}

Data are mean \pm SEM; $n=4-7$ mice per group. ${ }^{A} P<0.05$ compared with wild-type controls.

exogenous leptin on body weight and food intake between wild-type and BBS-knockout mice. Administration of mouse leptin i.p. $(1 \mu \mathrm{g} / \mathrm{g}$ body weight, twice a day for 4 days) caused a significant decrease in body weight and food intake in the wild-type mice (Figure 2). In contrast, i.p. leptin failed to significantly decrease body weight or food intake in Bbs2-, Bbs4-, and Bbs6-knockout mice. These data demonstrate that the obesity and hyperleptinemia observed in the BBS-knockout mice are associated with leptin resistance.

Defects in blood-brain transport do not account for leptin resistance in BBS-knockout mice. To gain insight into the mechanism of leptin resistance in BBS-knockout mice, we evaluated the role of the blood-brain barrier in the resistance to leptin in BBS-knockout mice. A decreased ability of leptin to cross the blood-brain barrier has been suggested to be an important mechanism of leptin resistance (33). Therefore, we first compared leptin concentrations in the cerebrospinal fluid (CSF) of wild-type and BBS-knockout mice to test whether high levels of circulating leptin translate into elevated CSF leptin levels. We found that CSF leptin levels were significantly greater $(P<0.05)$ in $B b s 2^{-/-}(2.09 \pm 0.57 \mathrm{ng} / \mathrm{ml}$; $n=8), B b s 4^{-/-}(3.90 \pm 1.39 \mathrm{ng} / \mathrm{ml} ; n=8)$, and $B b s 6^{-1-}(3.76 \pm 2.29 \mathrm{ng} / \mathrm{ml} ; n=5)$ mice than in wild-type mice $(0.17 \pm 0.10 \mathrm{ng} / \mathrm{ml}$; $n=4)$. Furthermore, the CSF/serum leptin ratio was not different between BBS-knockout mice and their wild-type littermates $(P=0.827)$. These data demonstrate that high circulating levels of leptin are associated with elevated CSF leptin levels, which suggests that endogenous leptin crosses the blood-brain barrier in BBS-knockout mice.

Next, we compared the effect of i.c.v. administration of leptin between wild-type and BBS-knockout mice. In wild-type mice, i.c.v. administration of leptin $(5 \mu \mathrm{g})$ caused a significant decrease in body weight and food intake (Figure 3). However, the appetite- and weight-reducing effects of leptin were significantly attenuated in Bbs4- and Bbs6-knockout mice as compared with wild-type animals. Furthermore, the effects of leptin on appetite and body weight were completely blunted in Bbs2-knockout mice. Administration of vehicle i.c.v. did not significantly alter food intake or body weight in BBSknockout and wild-type mice (Figure 3 ).

Finally, we compared the effect of i.c.v. administration of leptin on the weight of different fat depots between BBS-knockout mice and wild-type controls. As shown in Table 3, i.c.v. administration of leptin caused a significant decrease in brown adipose tissue (BAT), omental fat, and perirenal fat in wild-type mice. In contrast, i.c.v. administration of leptin did not significantly alter any of the fat depots in BBS-knockout animals (Table 3).

Decreased hypothalamic Pomc gene expression in BBS-knockout mice. To test whether the resistance of BBS-knockout mice to the catabolic actions of leptin is associated with alterations in the expression of downstream neuropeptides involved in the control of energy homeostasis, we compared the mRNA levels of POMC, AgRP, and NPY in the hypothalamus between BBS-knockout mice and wildtype controls. As shown in Figure 4, the expression of hypotha-

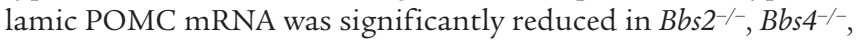
and $B b s 6^{-1-}$ mice. In contrast, the mRNA levels of AgRP and NPY were not significantly altered in BBS-knockout mice as compared with wild-type controls. These data indicate that there is a defect specifically in the POMC neurons that may account for the obesity phenotype of BBS-knockout mice.

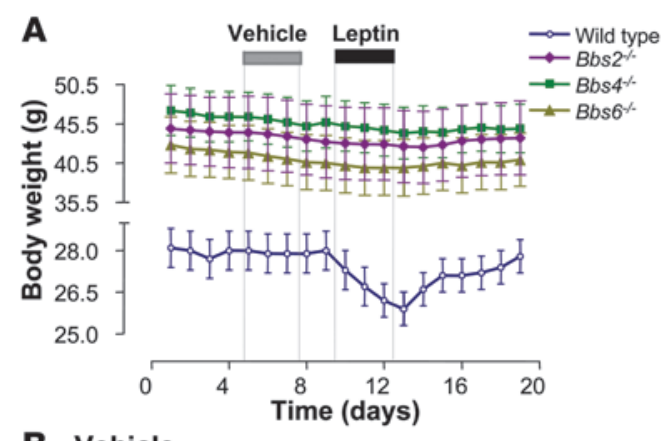

B Vehicle

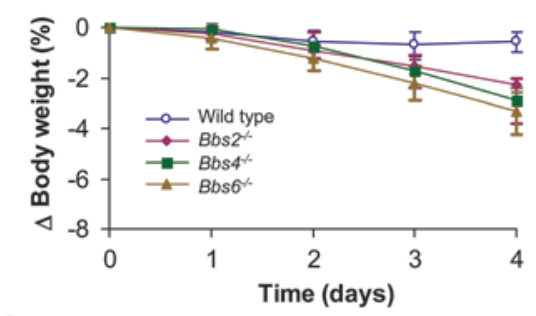

C Leptin

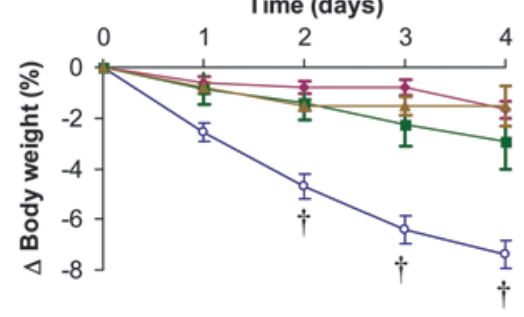

Figure 2

Change in body weight $(\mathbf{A}-\mathbf{C})$ and food intake (D-F) after intraperitoneal administration of vehicle or leptin (1 $\mathrm{\mu g} / \mathrm{g}$ body weight, twice daily) in $\mathrm{Bbs}^{-/-}, \mathrm{Bbs}^{-/-}$, and $\mathrm{Bbs6}^{-/-}$mice as compared with wild-type littermate controls. Data are mean \pm SEM; $n=9-22$ mice per group. ${ }^{\dagger} P<0.05$ compared with BBS-knockout mice. 
A
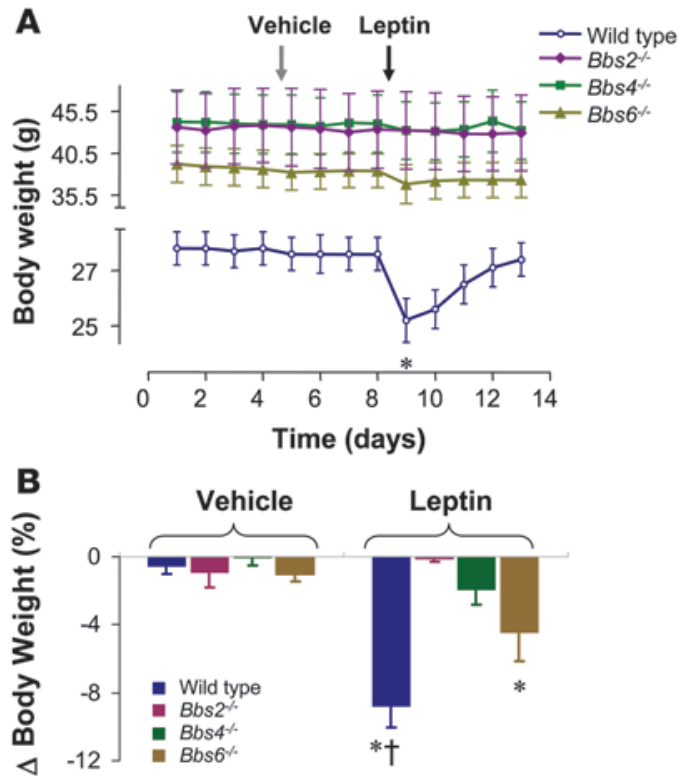
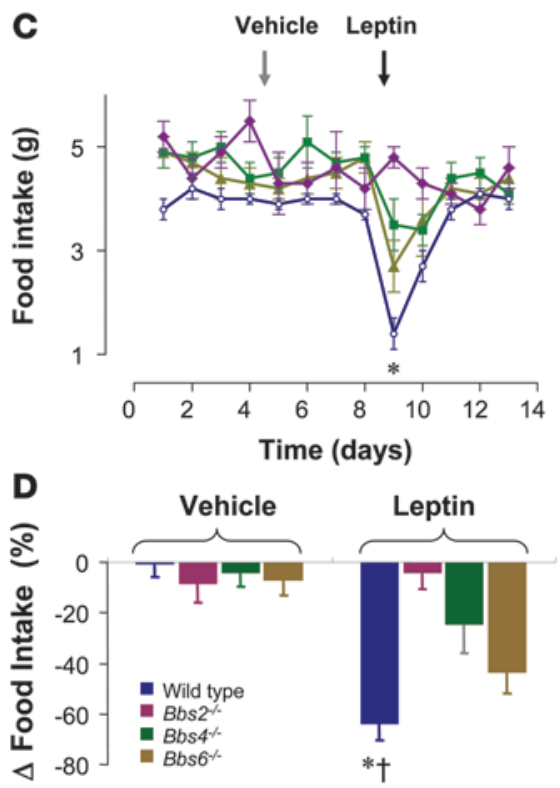

Figure 3

Change in body weight (A and B) and food intake (C and $\mathbf{D}$ ) after i.c.v. administration of vehicle or

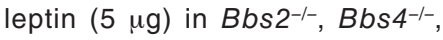
and $B b s 6^{-/-}$mice as compared with wild-type littermate controls. Data are mean \pm SEM; $n=8-12$ mice per group. ${ }^{\star} P<0.05$ compared with vehicle; ${ }^{\dagger} P<0.05$ compared with BBS-knockout mice.
Renal sympathetic nerve response to leptin is differentially altered in BBSknockout mice. Recently, we demonstrated in 2 mouse models of obesity (agouti obese mice and mice with diet-induced obesity) that leptin's ability to activate renal SNA is preserved despite resistance to the anorectic and weight-reducing effect of leptin $(31,32)$. To test whether obese BBS-knockout mice also have a preserved renal sympathetic nerve response to leptin, we compared the effect of i.c.v. administration of leptin on renal SNA between wild-type and BBSknockout mice. Interestingly, as shown in Figure 5 (A and B), baseline renal SNA was significantly greater in $\mathrm{Bbs4^{-/ }}$ and $\mathrm{Bbs6^{-/ }}$ mice than in wild-type controls. In contrast, baseline renal SNA in $\mathrm{Bbs2^{-/- }}$ mice was not significantly greater than that in wild-type animals.

As expected, i.c.v. administration of mouse leptin $(5 \mu \mathrm{g})$ caused a robust increase in renal SNA in wild-type mice (Figure 5C). Surprisingly, the renal SNA response to leptin was differentially affected by deletion of the $B b s$ genes. Indeed, $B b s 4^{-/-}$and $B b s 6^{--}$animals have a preserved renal sympathetic activation in response to leptin because the increase in renal SNA induced by leptin in these mice was comparable with that in the wild-type littermates. In contrast, $B b s 2^{-/-}$mice have an absent renal SNA response to leptin (Figure 5C). Because of the higher baseline renal SNA in $B b s 4^{-\gamma^{-}}$and $\mathrm{Bbs6}^{-\gamma_{-}^{-}}$mice, we also calculated the percentage change in renal SNA in response to leptin. When expressed as percentage change, leptin-induced renal sympathetic excitation tends to be attenuated in $B b s 4^{-/-}$and $B b s 6^{-/-}$mice (Figure 5D), but there was no statistical difference in the responses of these knockout mice compared with wild-type animals. In BBS- knockout and wild-type mice, i.c.v. administration of vehicle caused no significant change in renal SNA (data not shown).

Contrasting baseline arterial pressure in BBS-knockout mice. To test whether the obesity observed in BBS-knockout mice is associated with hypertension, we compared arterial pressure between wild-type and BBS-knockout mice (12-14 weeks old). Consistent with our previous report (23), we found that arterial pressure in the $B b s 6^{-/-}$mice was approximately $12 \mathrm{mmHg}$ higher than that in their wild-type littermate controls (Figure 6A). Arterial pressure was also greater, by approximately $13 \mathrm{mmHg}$, in $\mathrm{Bbs} 4^{-/-}$mice than in their wild-type littermates. However, $B b s 2^{-/-}$mice had normal arterial pressure compared with the wild-type controls (Figure 6A).

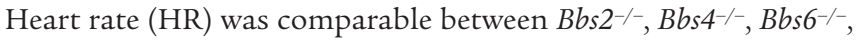
and wild-type controls (Figure 6B; $P=0.91$ ).

To examine whether the elevation of blood pressure is delayed in $B b s 2^{-/-}$mice, relative to $B b s 4^{--}$and $B b s 6^{-/-}$mice, we compared arterial pressure between older wild-type, Bbs2-, Bbs4-, and Bbs6-null mice (6-8 months; $n=6-7$ per group) in subsequent experiments. As with younger mice, an increase in mean arterial pressure (MAP) of approximately $15 \mathrm{mmHg}(P<0.001)$ was observed in Bbs4- and Bbs6-knockout mice, but no significant increase was detected in Bbs2-knockout mice $(116 \pm 2 \mathrm{mmHg}$ ) relative to wild-type controls $(115 \pm 1 \mathrm{mmHg})$. Thus, Bbs2 $2^{-1-}$ mice do not became hypertensive, even at later stages, despite the presence of obesity. Whereas all 3 of our BBS mouse models exhibited obesity, only $2\left(B b s 4^{--}\right.$and $\left.B b s 6^{-/-}\right)$were hypertensive. $B b s 2$-knockout mice did not develop high arterial pressure.

Table 3

Effect of i.c.v. leptin $(5 \mu \mathrm{g})$ on different fat depots in BBS-knockout mice

\begin{tabular}{|c|c|c|c|c|c|c|c|c|}
\hline \multirow[b]{2}{*}{ Parameter } & \multicolumn{2}{|c|}{ Wild type } & \multicolumn{2}{|c|}{ Bbs2-- } & \multicolumn{2}{|c|}{ Bbs4-/- } & \multicolumn{2}{|c|}{ Bbs6- $^{-/}$} \\
\hline & Vehicle & Leptin & Vehicle & Leptin & Vehicle & Leptin & Vehicle & Leptin \\
\hline BAT $(g)$ & $0.07 \pm 0.01$ & $0.05 \pm 0.01^{A}$ & $0.24 \pm 0.02$ & $0.25 \pm 0.03$ & $0.21 \pm 0.01$ & $0.21 \pm 0.01$ & $0.25 \pm 0.02$ & $0.24 \pm 0.02$ \\
\hline Reproductive fat (g) & $0.35 \pm 0.15$ & $0.19 \pm 0.06$ & $3.10 \pm 0.36$ & $3.54 \pm 0.23$ & $2.62 \pm 0.32$ & $2.29 \pm 0.31$ & $2.74 \pm 0.39$ & $2.04 \pm 0.25$ \\
\hline Omental fat $(\mathrm{g})$ & $0.26 \pm 0.05$ & $0.10 \pm 0.03^{A}$ & $1.39 \pm 0.14$ & $1.54 \pm 0.25$ & $1.76 \pm 0.17$ & $1.58 \pm 0.16$ & $1.55 \pm 0.36$ & $1.31 \pm 0.17$ \\
\hline Perirenal fat $(\mathrm{g})$ & $0.17 \pm 0.03$ & $0.08 \pm 0.03^{A}$ & $1.04 \pm 0.12$ & $0.82 \pm 0.17$ & $1.10 \pm 0.09$ & $1.16 \pm 0.17$ & $1.19 \pm 0.15$ & $1.05 \pm 0.26$ \\
\hline
\end{tabular}

Data are mean \pm SEM; $n=5$ mice per group. ${ }^{A} P<0.05$ compared with vehicle. 
POMC MRNA

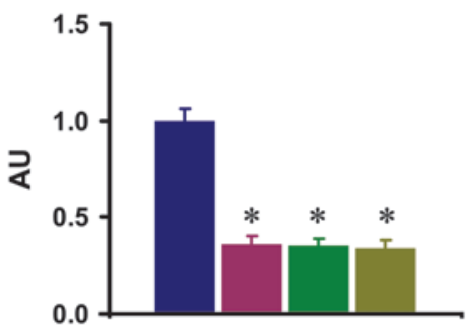

AgRP mRNA

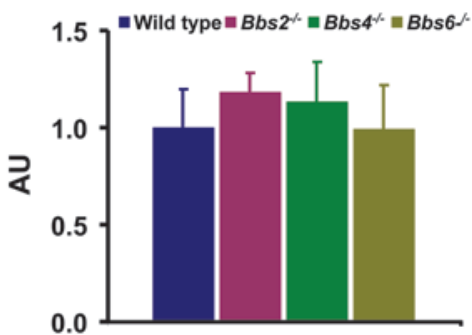

NPY mRNA

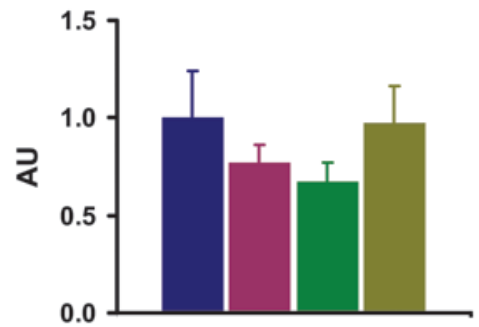

Figure 4

Hypothalamic mRNA levels of POMC, AgRP, and NPY in Bbs2 ${ }^{-1-}, B b s 4^{-/-}$, and $B b s 6^{-1-}$ mice as compared with wild-type littermate controls. Data are mean $\pm \mathrm{SEM} ; n=3$ per group. ${ }^{*} P<0.05$ compared with wild-type controls.

Exaggerated arterial pressure response to ganglionic blockade in Bbs4and Bbs6-null mice. The finding of elevated renal SNA in Bbs4- and $B b s 6$-knockout mice described above prompted us to examine the effects of inhibition of ganglionic transmission on arterial pres- sure. We compared the effect of ganglionic blockade with hexamethonium $(1 \mu \mathrm{g} / \mathrm{g}$ body weight, i.p.) on arterial pressure between BBS-knockout mice and wild-type controls. A summary and comparison of the peak of hexamethonium-induced arterial pres-
A

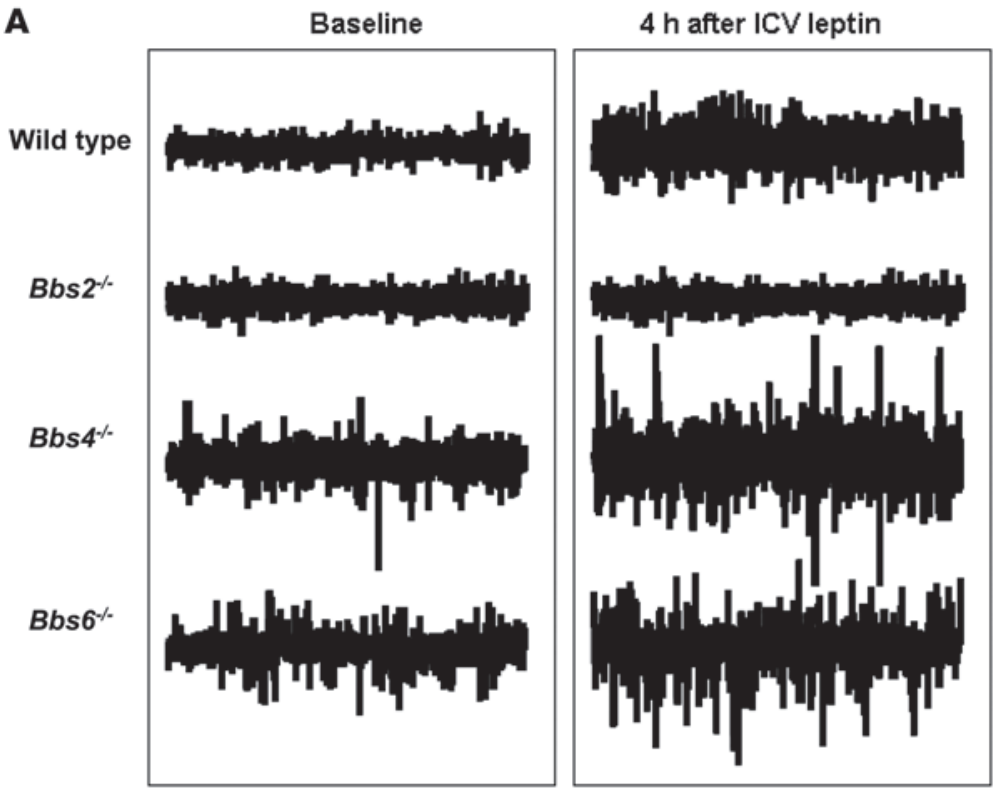

B

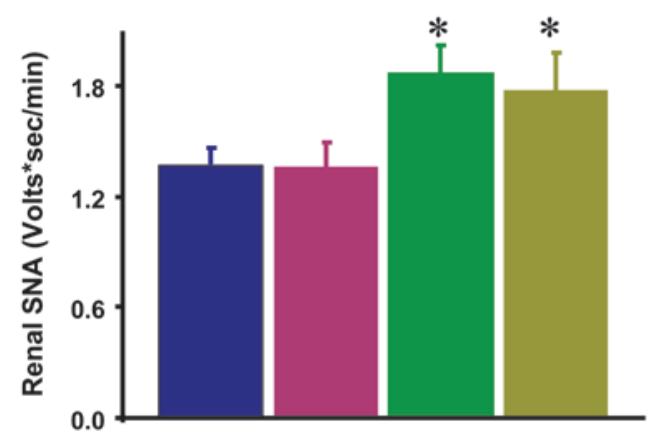

C
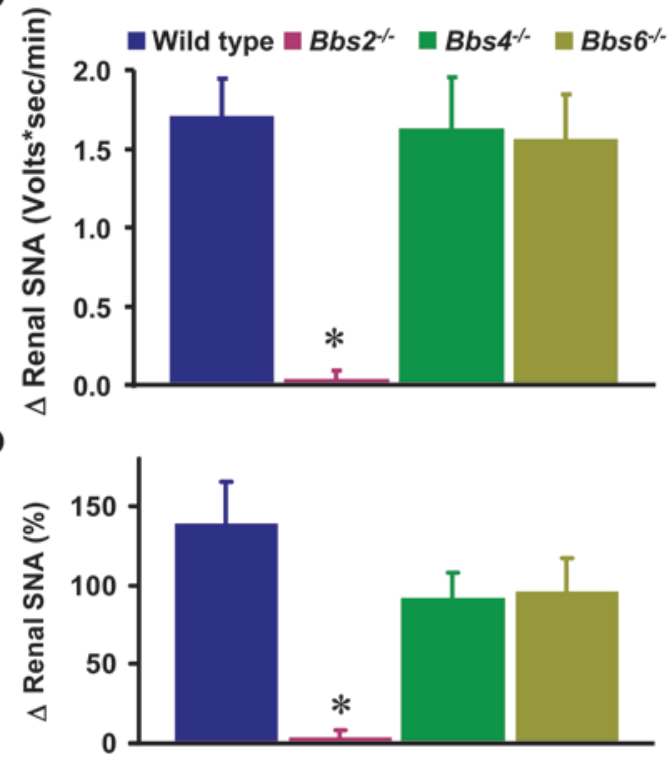

Figure 5

Comparison of renal SNA, at baseline and in response to leptin, between $B b s 2^{--}$, Bbs4 $4^{--}$, and $B b s 6^{-/-}$mice and wild-type littermate controls. (A) Segments of original records of renal SNA at baseline and 4 hours after leptin (5 $\mu$ g, i.c.v.). (B) Comparison of baseline renal SNA between wild-type and BBS mice ( $n=13-37$ mice per group). (C) Average renal SNA response 4 hours after leptin administration expressed as a function of time ( $n=10-16$ mice per group). (D) Average renal SNA response 4 hours after leptin administration expressed as the percentage change from baseline. Data are mean \pm SEM. ${ }^{*} P<0.05$ compared with wild-type controls. 

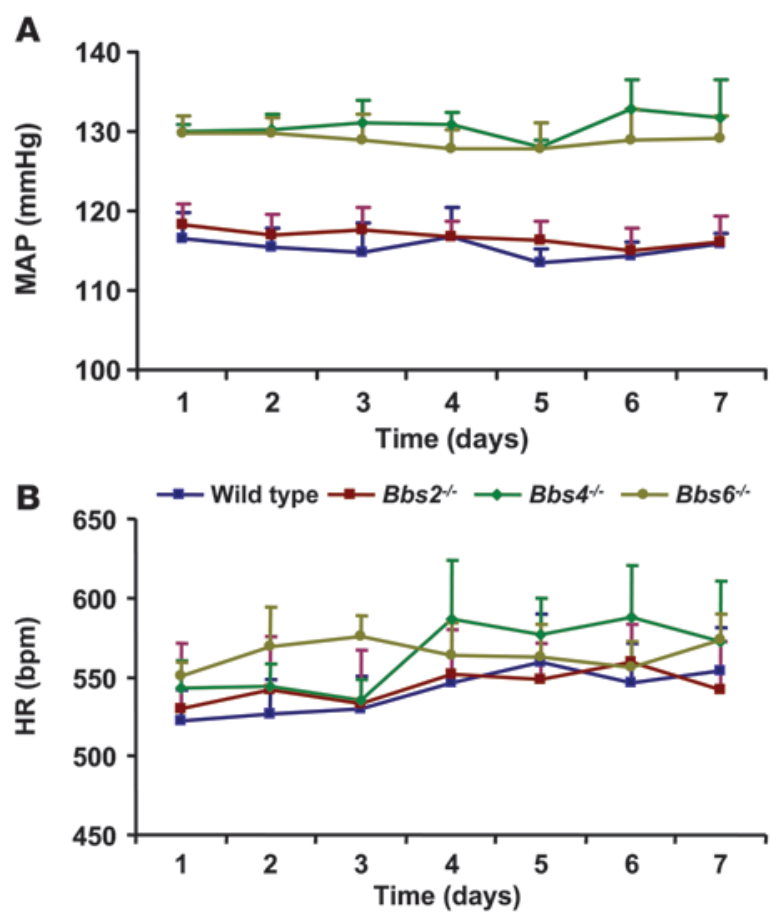

sure responses in wild-type and BBS mice are shown in Figure 7. Ganglionic blockade with hexamethonium caused equivalent

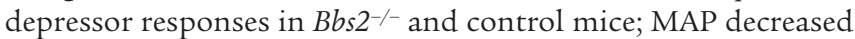
by approximately $17 \mathrm{mmHg}$. In contrast, hexamethonium caused a significantly greater reduction in $\mathrm{MAP}$ in $\mathrm{Bbs} 4^{-/-}$and $\mathrm{Bbs6}^{-/-}$mice (Figure 7A). The enhanced depressor response to hexamethonium in $\mathrm{Bbs4^{-/- }}$ and $\mathrm{Bbs}^{-/-}$relative to wild-type controls was also observed when the results were expressed as percentage change (Figure 7B). These results suggest that there is an exaggerated contribution of sympathetic tone to the maintenance of elevated arterial pressure in $B b s 4^{-/-}$and $B b s 6^{-/-}$mice.

Relevance of hyperleptinemia to the elevated arterial pressure in Bbs4 $4^{-1-}$ and $B b s 6^{-/}$mice. To test the role of hyperleptinemia in the elevated arterial pressure observed in $B b s 4^{-/-}$and $B b s 6^{-/-}$mice, we examined the effect of modulating circulating leptin levels on arterial pressure in these animals. The decrease in plasma leptin induced by fasting was associated with a significant decrease in MAP in both $B b s 4^{-/-}$and $B b s 6^{-/-}$mice (Figure 8). Reversing the decrease in plasma leptin during fasting with exogenous i.p. administration of leptin prevented the decrease in MAP in $\mathrm{Bbs}^{-/-}$and $\mathrm{Bbs}^{-/-}$mice (Figure 8), which indicates the importance of hyperleptinemia in maintaining arterial pressure elevation in these mice. Of note, the weight loss induced by fasting in $\mathrm{Bbs} 4^{---}$and $\mathrm{Bbs6^{-/- }}$ mice was similar regardless of whether the mice were treated with vehicle $(-12.2 \% \pm 1.5 \%$ and $-11.5 \% \pm 0.8 \%$, respectively) or leptin $(-13.1 \% \pm 1.2 \%$ and $-12.0 \% \pm 1.6 \%$, respectively), which further demonstrates the resistance of these mice to the metabolic actions of leptin.

\section{Figure 7}

Change in MAP induced by intraperitoneal administration of hexamethonium (1 $\mu \mathrm{g} / \mathrm{g}$ body weight) in $\mathrm{Bbs2}^{-/-}, \mathrm{Bbs}^{-/-}$, and $\mathrm{Bbs6}^{-/-}$mice and wild-type littermate controls expressed in $\mathrm{mmHg}(\mathbf{A})$ and as the percentage change from baseline $(B)$. Data are mean \pm SEM; $n=5-10$ mice per group. ${ }^{*} P<0.05$ compared with wild-type controls.

\section{Figure 6}

Comparison of MAP (A) and HR (B) between Bbs2 ${ }^{-/-}, \mathrm{Bbs}^{4^{--}}$, and $B b s 6^{-1-}$ mice and wild-type littermate controls. Data are mean \pm SEM of MAP and HR recorded continuously for 24 hours over 7 days

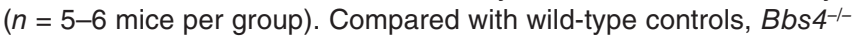
and $B b s 6^{-/-}$mice had significantly elevated MAP $(P<0.001)$, but Bbs2 $^{-1-}$ mice did not $(P=0.678)$.

Suppression of hyperleptinemia by a 48-h fast also normalized baseline renal SNA in $B b s 4^{-/-}$mice, as indicated by the finding that renal SNA was comparable between wild-type controls $(1.33 \pm 0.15$ volts $\times \mathrm{s} / \mathrm{min} ; n=4)$ and fasted $B b s 4^{-/-}$mice $(1.24 \pm 0.08$ volts $\times$ $\mathrm{s} / \mathrm{min} ; n=3)$. As for the arterial pressure, renal SNA remained elevated in fasted $B b s 4^{-/}$mice given exogenous leptin i.p. (1.99 \pm 0.07 volts $\times \mathrm{s} / \mathrm{min} ; n=3)$. These results indicate that the increased renal SNA in $B b s 4^{-/-}$mice was due to hyperleptinemia.

Normal cardiac phenotype in BBS-knockout mice. Cardiac abnormalities have been reported in BBS patients $(4,34)$. To determine whether BBS-knockout mice have cardiac defects, we performed echocardiography in conscious mice (14-20 weeks of age). As shown in Table 4, heart weight and echocardiographic data were not different between BBS mice and wild-type mice. In agreement with our radiotelemetry data, HR measured by echocardiography was also comparable between BBS-knockout mice and wild-type controls $(P=0.286)$. To assess whether cardiac abnormalities may be slow in onset and develop at later stages, we performed echocardiography in older (6-12 months) $B b s 6^{-/-}$mice and wild-type control littermates ( $n=5$ each). No significant difference in the echocardiography data was observed between older $B b s 6^{-/-}$and wild-type mice (data not shown).

\section{Discussion}

Obesity and cardiovascular disease are common in BBS. However, limited data on the mechanisms underlying the pathogenesis of these conditions in BBS are available. In the present study, we

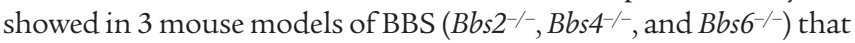
obesity was associated with hyperleptinemia, resistance to the anorectic and weight-reducing effects of leptin, and decreased hypothalamic POMC mRNA levels. Furthermore, we demonstrated that

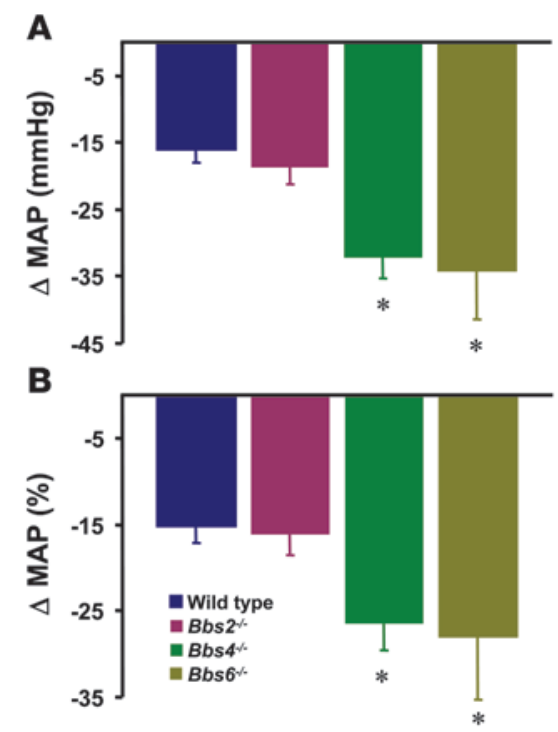




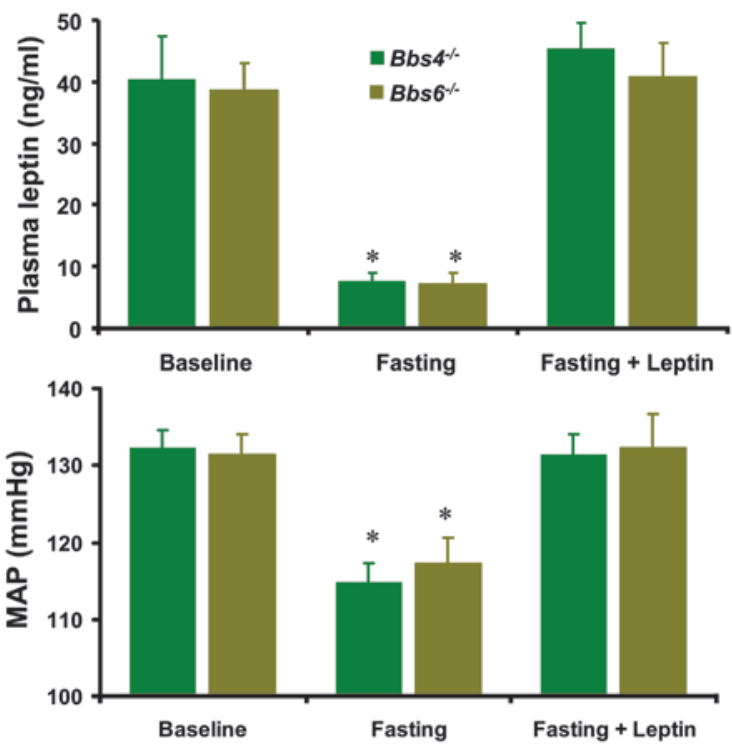

Bbs4- and Bbs6-knockout mice also develop elevated blood pressure, whereas Bbs2-knockout mice do not. Interestingly, the mice with hypertension exhibited an increase in renal sympathetic nerve drive, a preserved renal sympathetic activation in response to leptin, and a greater reduction in arterial pressure in response to ganglionic blockade. The elevated arterial pressure observed in $\mathrm{Bbs4^{-/ }}$ and $B b s 6^{-/-}$mice was reversed when hyperleptinemia was suppressed by fasting, but was maintained when hyperleptinemia was sustained in fasted mice treated with exogenous leptin. Thus, whereas all 3 BBS mice were resistant to the metabolic actions of leptin, $B b s 4^{-/-}$and $B b s 6^{-/-}$mice remained responsive to the effects of leptin on renal SNA and arterial pressure, which led to hypertension.

Despite the predominance of obesity in BBS (34), including morbid obesity (body mass index $>40 \mathrm{~kg} / \mathrm{m}^{2}$ ), little is known about the biochemical and physiological abnormalities leading to energy imbalance in this syndrome. Our data indicate that the development of obesity in BBS mice is associated with increased food intake and decreased locomotor activity. Interestingly, the decrease in locomotor activity (44\%-53\%) in BBS-null mice seemed to be more pronounced than in non-BBS obese mice, although body weight was comparable in both groups of mice. Indeed, the body weight ( $39 \pm 1 \mathrm{~g}$ ) of C $57 \mathrm{BL} / 6 \mathrm{~J}$ mice that consumed a high-fat (45\%) diet for 20 weeks was comparable with that in BBS-null mice (Table 1 ), but their locomotor activity was decreased by only $30 \%$ compared with the lean controls (K. Rahmouni, unpublished observations). In agreement with our results, Grace et al. (35) showed a

\section{Figure 8}

Effect of a 48-hour fast, with or without leptin administration, on plasma leptin and MAP in $\mathrm{Bbs4}^{-/-}$and $\mathrm{Bbs6}^{-/-}$mice. MAP during fasting (with or without leptin administration) represents the average of the last 24 hours of the fasting period. Data are mean \pm SEM; $n=8$ mice per group. ${ }^{*} P<0.05$ compared with baseline and fasting+leptin.

lower level of physical activity in subjects with BBS than in healthy control subjects, despite comparable body mass indexes. In the present study, we also showed that pair-feeding is not sufficient to normalize fat mass in BBS mice. Taken together, these data suggest that the obesity associated with BBS is caused by a combination of increased energy intake and decreased energy expenditure.

Our findings also indicated that defects in leptin action are involved in the obesity associated with BBS. Indeed, we found that BBS mice have high circulating levels of leptin, even at an early age before any difference in body weight can be detected. Hyperleptinemia is usually considered to reflect a state of leptin resistance, which often predicts a loss of metabolic responsiveness to leptin (33). However, emerging evidence indicates that obesity can develop independently from defects in leptin action $(36,37)$. For instance, mice null for neuromedin $\mathrm{U}$ are obese and hyperleptinemic, but have a preserved metabolic response to the exogenous administration of leptin (37). In BBS mice, we found that systemic administration of leptin failed to decrease body weight and food intake, which indicates that these animals are resistant to the appetite-suppressant and weight-reducing actions of exogenous leptin.

The high circulating levels of leptin in the CSF of BBS mice indicate that endogenous leptin does cross the blood-brain barrier in these animals and argue against a meaningful role for transport defects in the resistance to leptin. This would seem to indicate that leptin resistance is due to defects in the action of leptin at the receptor level and/or in the downstream pathways. Our finding of a reduced expression in the Pomc gene, but not in the Agrp and Npy genes, supports the notion that the obese phenotype observed in BBS-knockout mice is likely due to a defect in POMC neurons. In the hypothalamus, many of the leptin-responsive neurons are ciliated (38), and immunoreactivity of the leptin receptor has been shown to be enriched in the cilia membranes of neurons of the olfactory mucosa (39). Given the importance of BBS proteins to ciliary function, their absence could lead to defects in the neuronal cilia and alter the signaling machinery associated with the leptin receptor. Alternatively, an effect on intracellular transport resulting from a defect in $B b s$ genes could lead to abnormal intracellular trafficking of the leptin receptor or other signaling machinery. In support of this, intracellular ves-

Table 4

Heart weight and echocardiography findings in BBS mice

\begin{tabular}{|c|c|c|c|c|c|c|c|c|}
\hline Genotype & HW (g) & $\operatorname{EDV}(\mu \mathrm{l})$ & ESV $(\mu l)$ & LVm (mg) & Vol/LVm $(\mu \mathrm{l} / \mathrm{mg})$ & SV $(\mu \mathrm{l})$ & $\mathrm{CO}(\mu \mathrm{l} / \mathrm{m})$ & EF (\%) \\
\hline Wild type & $0.15 \pm 0.10$ & $45 \pm 3$ & $12.2 \pm 1.6$ & $93 \pm 5$ & $0.49 \pm 0.03$ & $33 \pm 3$ & $14,497 \pm 1,416$ & $0.74 \pm 0.02$ \\
\hline $\mathrm{Bbs2}^{--}$ & $0.14 \pm 0.10$ & $43 \pm 3$ & $13.5 \pm 2.9$ & $81 \pm 4$ & $0.54 \pm 0.05$ & $29 \pm 3$ & $13,323 \pm 1,906$ & $0.69 \pm 0.05$ \\
\hline Bbs4-/- & $0.14 \pm 0.10$ & $42 \pm 7$ & $8.6 \pm 2.0$ & $104 \pm 7$ & $0.39 \pm 0.04$ & $33 \pm 6$ & $17,142 \pm 3,568$ & $0.78 \pm 0.05$ \\
\hline $\mathrm{Bbs6}^{-/-}$ & $0.14 \pm 0.10$ & $52 \pm 9$ & $14.8 \pm 5$ & $90 \pm 17$ & $0.69 \pm 0.18$ & $37 \pm 5$ & $13,015 \pm 2,696$ & $0.75 \pm 0.05$ \\
\hline
\end{tabular}

Data are mean \pm SEM; $n=7-20$ mice per group. HW, heart weight; EDV, left ventricular end-diastolic volume; ESV, left ventricular end-systolic volume; LVm, left ventricular mass; Vol/LVm, left ventricular end-diastolic volume/LVm ratio; SV, left ventricular stroke volume; CO, cardiac output; EF, left ventricular ejection fraction. 
icle trafficking has been shown to be compromised in zebrafish BBS-knockout models (40). Additional experiments are required to test these hypotheses.

In Bbs4- and Bbs6-knockout mice, i.c.v. administration of leptin was also able to increase sympathetic nerve drive to the kidney. This finding suggests that, at least in Bbs4- and Bbs6-null mice, the leptin receptor is present, because the absence of the long form of the leptin receptor, as observed in $\mathrm{db} / \mathrm{db}$ mice, leads to complete loss of renal sympathetic activation in response to leptin (41). The finding of preserved leptin-induced renal sympathetic activation in Bbs4- and Bbs6-knockout mice agrees with our previous findings in agouti obese and diet-induced obese mice, i.e., that leptin resistance is selective, sparing the renal sympathetic response (32). Interestingly, preservation of leptin's ability to activate renal SNA in Bbs4- and Bbs6-knockout mice is associated with higher baseline sympathetic nerve tone. In addition to exhibiting elevated renal sympathetic outflow, Bbs4- and Bbs6-knockout mice exhibited increased arterial pressure just like the agouti obese and dietinduced obese mice. Of importance, Bbs2-knockout mice that did not have elevated arterial pressure also did not have elevated renal SNA and were resistant to the renal sympathetic action of leptin. The preserved renal sympathetic activation in response to leptin, in association with high CSF leptin levels, indicates that leptin may be the main cause of hypertension and enhanced sympathetic drive, which are associated with Bbs4 and Bbs6 genotypes. This notion is supported by the finding that suppression of hyperleptinemia after fasting normalized arterial pressure and renal sympathetic tone in these mice, but sustaining the hyperleptinemia in the fasted mice with exogenous leptin administration prevented the decrease in arterial pressure and renal sympathetic outflow.

The exaggerated depressor response to hexamethonium in Bbs4and Bbs6-knockout mice indicates that the elevated arterial pressure observed in these animals is sympathetically mediated. This finding is consistent with the elevated renal sympathetic tone observed in these mice. The kidney is known to play a major role in the control of cardiovascular function and blood pressure. The renal effects of an increased renal sympathetic drive lead to renal sodium retention, a decrease in renal blood flow and the glomerular filtration rate, renal vasoconstriction, and an increase in renin release (42). These alterations are known to promote increases in arterial pressure. Diet-induced obesity is accompanied by an elevation in renal sympathetic outflow (43), and renal denervation attenuated the increase in arterial pressure associated with dietary obesity (44).

Our current finding of an elevated arterial pressure in Bbs4- and $B b s 6$-knockout mice but not in Bbs2-knockout mice is particularly interesting because Moore et al. (34) reported that, in humans, all BBS genotypes (including BBS4 and BBS6) are accompanied by hypertension, except for BBS2. This supports the appropriateness of our mouse models for the study of hypertension in human BBS. In another study, non-BBS individuals with particular variants of BBS4 and BBS6, but not BBS2, were found to be at higher risk of developing hypertension (5). Our BBS mouse models thus provide the opportunity to gain insight into the mechanisms involved in the pathophysiological processes of obesity-induced hypertension. Elucidation of the mechanisms that protect some obese patients from developing hypertension, as in BBS2, will further the understanding of the pathophysiology of obesity-associated hypertension.

It was recently shown that 7 of the 12 known BBS proteins, including BBS2 and BBS4, form a core complex known as the BBSome (45). BBS6 is not part of the BBSome, but rather has homology to chaperonins. It is currently only speculative whether BBS6 is involved in BBSome formation. It is of interest that both Bbs2- and Bbs4-knockout mice would be expected to have abnormal BBSome function, yet have different phenotypes with respect to elevated arterial pressure, renal sympathetic nerve tone, and resistance to the renal sympathetic action of leptin. These findings indicate a difference in BBSome function, depending on whether the BBS2 or BBS4 component of the complex is missing. Alternatively, some components of the BBSome could have functions separate from their function as a component of the BBSome.

With respect to cardiac function evaluated by echocardiography, we found that $B b s 2^{-{ }^{--}}, B b s 4^{-/}$, and $B b s 6^{-/-}$mice did not have any cardiac alterations. Few studies have analyzed the cardiac function in BBS patients. In one study, $32 \%$ of BBS patients showed some type of abnormalities on echocardiography (4). In another study, congenital heart defects were noted in 3 of 46 BBS patients (34). However, in both studies, the genotype of BBS patients with a heart defect was not reported. Whether the deletion of $B b$ s genes, other than those considered here, in mice would recapitulate the cardiac abnormalities observed in BBS patients remains to be determined. Also, we cannot exclude cardiac defects as a cause of a less than predicted number (based on Mendelian ratios) of homozygous BBS-knockout mice $(21,22)$.

In conclusion, BBS-knockout mouse models provide an appropriate tool for studying BBS. Further study of these animals may help elucidate the pathophysiological mechanisms of the diseases associated with BBS, including obesity and hypertension.

\section{Methods}

Animals. For each genotype, homozygous knockout (-/-) and littermate control (+/+) mice were produced by crossing heterozygous mice with a mixed genetic background of C57BL/6J and 129/SvEv mice. Genotyping was performed by PCR as described previously $(21,22)$. Animals were housed in a room maintained at a constant temperature $\left(23^{\circ} \mathrm{C}\right)$ and a 12 -hour light/12-hour dark cycle (lights turned off at $6 \mathrm{pm}$ ) and had free access to standard mouse chow (Harlan Teklad) and tap water. For the pair-feeding studies, mice were housed in individual cages, and a knockout animal was given the amount of food consumed the day before by a sex-matched wildtype littermate. Imaging of fat by MRI was performed after the animals were anesthetized $(91 \mathrm{mg} / \mathrm{kg}$ ketamine and $9.1 \mathrm{mg} / \mathrm{kg}$ xylaxine, i.p.) using a Varian Unity/Inova 4.7 T small-bore MRI system (Varian Inc.). The acquisition consisted of a T1-weighted fast spin-echo sequence (repetition time/ echo time $=625 / 12 \mathrm{~ms}$ ) with an in-plane resolution of $0.13 \times 0.25 \mathrm{~mm}^{2}$ and a slice thickness of $1 \mathrm{~mm}$ acquired in the axial and coronal planes. To quantify the fat tissues of BBS and wild-type mice, different fat depots were dissected at sacrifice and weighed. Implantation of cannulae i.c.v. was performed as described previously (32). Mice were given at least 1 week to recover from surgery before the experiments began. The University of Iowa Animal Research Committee approved all protocols.

Effects of leptin on food intake, body weight, and fat depots. The feeding and body weight responses to leptin were compared between wild-type and BBS-null mice. Each mouse was housed individually starting at least 1 week before the study. The body weight and food intake of each mouse were measured daily between 9 and 10 am for 4 consecutive days before the vehicle treatment began ( $1 \mu \mathrm{l} / \mathrm{g}$ body weight i.p., twice daily for 4 days). One day after the end of vehicle treatment, mouse leptin ( $1 \mu \mathrm{g} / \mathrm{g}$ body weight) was injected i.p. into the same mice twice daily for 4 days. Other groups of mice were assigned to receive i.c.v. administration of single injections of vehicle $(1 \mu \mathrm{l})$ or leptin $(5 \mu \mathrm{g} /$ mouse). Body weight and food intake were measured every day throughout the treatments and 5-6 days thereafter. To 
test the effect of i.c.v. administration of leptin on the weight of fat depots, wild-type and BBS-null mice were treated with either vehicle or leptin $(5 \mu \mathrm{g} /$ mouse) i.c.v. For each genotype, the mice treated with vehicle and leptin were weight-matched. Mice were sacrificed 24 hours after i.c.v. treatments, and the weight of individually dissected BAT, reproductive fat, omental fat, and perirenal fat depots was measured.

Recording of renal SNA. Mice were anesthetized by i.p. injection of ketamine $(91 \mathrm{mg} / \mathrm{kg})$ and xylaxine $(9.1 \mathrm{mg} / \mathrm{kg})$. Catheters were introduced into a carotid artery and jugular vein for the measurement of hemodynamic variables and the administration of anesthetic ( $\alpha$-chloralose), respectively. To measure direct multifiber renal SNA, a nerve fascicle to the left kidney was carefully isolated. A bipolar platinum-iridium electrode (Cooner Wire) was suspended under the nerve and secured with silicone gel (Kwik-Cast; WPI). The nerve signal was amplified and filtered as described previously (32).

Baseline renal SNA and hemodynamic variables were recorded for 10 minutes. An average of 2 separate measurements during the 10 -minute control period was considered the baseline value for each animal. Leptin $(5 \mu \mathrm{g})$ or vehicle $(2 \mu \mathrm{l})$ was then administered i.c.v. The renal SNA response to leptin or vehicle was recorded continuously for 240 minutes. Anesthesia was sustained with the administration of $\alpha$-chloralose $(25 \mathrm{mg} / \mathrm{kg} / \mathrm{h})$ intravenously. Body temperature was maintained at $37.5^{\circ} \mathrm{C}$ with the assistance of a lamp and a heating pad. At the end of the study, mice were euthanized with a lethal dose of ketamine and xylazine. The integrated voltage after death (background noise) was subtracted from the total integrated voltage to calculate real renal SNA.

Measurement of arterial pressure. Arterial pressure was recorded in conscious mice using continuous radiotelemetric measurement. Mice were anesthetized i.p. with a ketamine and xylaxine cocktail. The left common carotid artery was isolated, and the catheter was inserted and tied securely using silk. The transmitter was slipped under the skin and down into a dissected free "pocket" along the flank, as close to the right hind limb as possible. The neck incision was closed using silk and then was further sealed with tissue adhesive. Mice were kept warm on a heating pad and monitored closely until they fully recovered from anesthesia.

The animals were allowed to recover for several days before arterial pressure, HR, and locomotor activity were recorded continuously in the conscious unrestrained state for 7 days. The effect of ganglionic blockade (hexamethonium, $1 \mu \mathrm{g} / \mathrm{g}$ body weight, i.p.) on basal arterial pressure was then examined. Measurements were recorded for 10 seconds every 5 minutes and stored on a personal computer using Data Science Dataquest software.

To study the relevance of hyperleptinemia to the hypertension associated with BBS, $B b s 4^{-/-}$and $B b s 6^{-/-}$mice were equipped for radiotelemetry measurement and allowed to recover for several days as described above. Baseline MAP was recorded over 3 days, after which the mice were fasted for 48 hours. During fasting, mice were treated i.p. (twice daily) with vehicle or leptin. Leptin was administered in incremental dose $(0.5,1,1.5$, and $2 \mu \mathrm{g} / \mathrm{g}$ body weight). In a pilot study, we found that such i.p. leptin treatment maintained hyperleptinemia in fasted $B b s 4^{-/-}$and $B b s 6^{-/-}$mice. One week later, during fasting again for 48 hours, the $B b s 4^{-/-}$and $B b s 6^{-/-}$mice received the inverse treatment, i.e., the mice treated with vehicle and leptin, respectively, in the first fasting period were given leptin and vehicle, respectively, in the second fasting period. Blood for plasma leptin assay was col- lected from the tail vein of each mouse at baseline (just before the recording of baseline MAP began) and at the end of each fasting period.

Echocardiography. Two-dimensional echocardiography was performed as previously described (46). Mice were lightly sedated with midazolam $(0.15 \mathrm{mg}$, s.c.), which allowed the mice to remain conscious but docile. The following indices of cardiac function were measured: left ventricular end-diastolic volume, left ventricular end-systolic volume, left ventricular mass, left ventricular end-diastolic volume divided by the left ventricular mass ratio, left ventricular stroke volume, cardiac output, and left ventricular ejection fraction.

Analysis of hypothalamic neuropeptide expression. Mice were sacrificed by $\mathrm{CO}_{2}$ asphyxiation, and mediobasal hypothalami were excised and mRNA extracted using Tri reagent. Real-time RT-PCR was used to compare the mRNA levels of POMC, NPY, and AgRP between the control and BBS-knockout mice. The primers used were as follows: $5^{\prime}$-CTGCTTCAGACCTCCATAGATGTG3' (forward POMC), 5'-CAGCGAGAGGTCGAGTTTGC-3' (reverse POMC); 5'-TCAGACCTCTTAATGAAGGAAAGCA-3' (forward NPY), 5'-GAGAACAAGTTTCATTTCCCATCA-3' (reverse NPY); and 5'-CAGAAGCTTTGGCGGAGGT-3' (forward AgRP), 5'-AGGACTCGTGCAGCCTTACAC-3' (reverse AgRP). RPL19 was used as an internal control.

Leptin measurements. Leptin was measured in plasma and CSF. Plasma was obtained by centrifuging the blood collected from the mice at 2,040 $\mathrm{g}$ for 8 minutes. For the collection of CSF, each mouse was anesthetized with a ketamine and xylazine cocktail and then positioned in a stereotaxic apparatus with the neck flexed. An incision was then made to expose the membrane located in the area between the occipital notch and the first cervical vertebrae. Once the membrane was exposed, a 20- $\mu$ l Hamilton syringe was used to puncture the membrane and, immediately, the CSF was carefully suctioned out; only clear CSF was used. Mice were sacrificed after the blood was collected. Murine leptin concentrations were measured by radioimmunoassay using a commercially available kit (Crystal Chem Inc.).

Statistics. Results are expressed as mean \pm SEM. Data were analyzed using 1- or 2-way ANOVA. When ANOVA indicated significance, Fisher's test was used to compare the mean values between the different groups of mice. $P<0.05$ was considered significant.

\section{Acknowledgments}

We thank Mike Andrews and Donald A. Morgan for assisting with mouse maintenance and SNA experiments, respectively, and Allyn L. Mark and Ruth Swiderski for critically reading the manuscript and making helpful comments. This work was supported by grants from the American Heart Association (to K. Rahmouni) and the NIH (to K. Rahmouni and V.C. Sheffield). V.C. Sheffield is an investigator of the Howard Hughes Medical Institute.

Received for publication April 10, 2007, and accepted in revised form January 16, 2008.

Address correspondence to: Kamal Rahmouni, Center on Functional Genomics of Hypertension, Department of Internal Medicine, University of Iowa Carver College of Medicine, 3135C MERF, Iowa City, Iowa 52242, USA. Phone: (319) 353-5256; Fax: (319) 353-5350; E-mail: kamal-rahmouni@uiowa.edu.
1. Green, J.S., et al. 1989. The cardinal manifestations of Bardet-Biedl syndrome, a form of Laurence-MoonBiedl syndrome. N. Engl. J. Med. 321:1002-1009.

2. Blacque, O.E., and Leroux, M.R. 2006. BardetBiedl syndrome: an emerging pathomechanism of intracellular transport. Cell. Mol. Life Sci. 63:2145-2161

3. Harnett, J.D., et al. 1988. The spectrum of renal disease in Laurence-Moon-Biedl syndrome. N. Engl. J.
Med. 319:615-618.

4. Elbedour, K., Zucker, N., Zalzstein, E., Barki, Y., and Carmi, R. 1994. Cardiac abnormalities in the Bardet-Biedl syndrome: echocardiographic studies of 22 patients. Am. J. Med. Genet. 52:164-169.

5. Benzinou, M., et al. 2006. Bardet-Biedl syndrome gene variants are associated with both childhood and adult common obesity in French Caucasians. Diabetes. 55:2876-2882.
6. Mykytyn, K., et al. 2002. Identification of the gene (BBS1) most commonly involved in Bardet-Biedl syndrome, a complex human obesity syndrome. Nat. Genet. 31:435-438.

7. Nishimura, D.Y., et al. 2001. Positional cloning of a novel gene on chromosome 16q causing Bardet-Biedl syndrome (BBS2). Hum. Mol. Genet. 10:865-874.

8. Chiang, A.P., et al. 2004. Comparative genomic analysis identifies an ADP-ribosylation factor-like 
gene as the cause of Bardet-Biedl syndrome (BBS3). Am. J. Hum. Genet. 75:475-484.

9. Mykytyn, K., et al. 2001. Identification of the gene that, when mutated, causes the human obesity syndrome BBS4. Nat. Genet. 28:188-191.

10. Li, J.B., et al. 2004. Comparative and basal genomics identifies a flagellar and basal body proteome that includes the BBS5 human disease gene. Cell. 117:541-552.

11. Slavotinek, A.M., et al. 2000. Mutations in MKKS cause Bardet-Biedl syndrome. Nat. Genet. 26:15-16.

12. Badano, J.L., et al. 2003. Identification of a novel Bardet-Biedl syndrome protein, BBS7, that shares structural features with BBS1 and BBS2. Am.J. Hum. Genet. 72:650-658.

13. Ansley, S.J., et al. 2003. Basal body dysfunction is a likely cause of pleiotropic Bardet-Biedl syndrome. Nature. 425:628-633.

14. Nishimura, D.Y., et al. 2005. Comparative genomics and gene expression analysis identifies BBS9, a new Bardet-Biedl syndrome gene. Am. J. Hum. Genet. 77:1021-1033.

15. Stoetzel, C., et al. 2006. BBS10 encodes a vertebratespecific chaperonin-like protein and is a major BBS locus. Nat. Genet. 38:521-524.

16. Chiang, A.P., et al. 2006. Homozygosity mapping with SNP arrays identifies TRIM32 an E3 ubiquitin ligase, as a Bardet-Biedl syndrome gene (BBS11). Proc. Natl. Acad. Sci. U. S. A. 103:6287-6292.

17. Stoetzel, C., et al. 2007. Identification of a novel BBS gene (BBS12) highlights the major role of a vertebrate-specific branch of chaperonin-related proteins in Bardet-Biedl syndrome. Am. J. Hum. Genet. 80:1-11.

18. Ansley, S.J., et al. 2003. Basal body dysfunction is a likely cause of pleiotropic Bardet-Biedl syndrome. Nature. 425:628-633.

19. Badano, J.L., Mitsuma, N., Beales, P.L., and Katsanis, N. 2006. The ciliopathies: an emerging class of human genetic disorders. Annu. Rev. Genomics Hum. Genet. 7:125-148.

20. Chiang, A.P., et al. 2004. Comparative genomic analysis identifies an ADP-ribosylation factor-like gene as the cause of Bardet-Biedl syndrome (BBS3). Am. J. Hum. Genet. 75:475-584.
21. Nishimura, D.Y., et al. 2004. Bbs2-null mice have neurosensory deficits, a defect in social dominance, and retinopathy associated with mislocalization of rhodopsin. Proc. Natl. Acad. Sci. U. S. A. 101:16588-16593.

22. Mykytyn, K., et al. 2004. Bardet-Biedl syndrome type 4 (BBS4)-null mice implicate Bbs4 in flagella formation but not global cilia assembly. Proc. Natl. Acad. Sci. U. S. A. 101:8664-8669.

23. Fath, M.A., et al. 2005. Mkks-null mice have a phenotype resembling Bardet-Biedl syndrome. Hum. Mol. Genet. 14:1109-1118.

24. Ross, A.J., et al. 2005. Disruption of Bardet-Biedl syndrome ciliary proteins perturbs planar cell polarity in vertebrates. Nat. Genet. 37:1135-1140.

25. Morton, G.J., Cummings, D.E., Baskin, D.G., Barsh, G.S., and Schwartz, M.W. 2006. Central nervous system control of food intake and body weight. Nature. 443:289-295.

26. Friedman, J.M., and Halaas, J.L. 1998. Leptin and the regulation of body weight in mammals. Nature. 395:763-770.

27. Banks, W.A., Kastin, A.J., Huang, W., Jaspan, J.B., and Maness, L.M. 1996. Leptin enters the brain by a saturable system independent of insulin. Peptides. 17:305-311.

28. Elmquist, J.K., Bjorbaek, C., Ahima, R.S., Flier, J.S., and Saper, C.B. 1998. Distributions of leptin receptor mRNA isoforms in the rat brain. J. Comp. Neurol. 395:535-547.

29. Schwartz, M.W., and Porte, D., Jr. 2005. Diabetes, obesity, and the brain. Science. 307:375-379.

30. Rahmouni, K., Correia, M.L., Haynes, W.G., and Mark, A.L. 2005. Obesity-associated hypertension: new insights into mechanisms. Hypertension. 45:9-14.

31. Correia, M.L., et al. 2002. The concept of selective leptin resistance: evidence from agouti yellow obese mice. Diabetes. 51:439-442.

32. Rahmouni, K., Morgan, D.A., Morgan, G.M., Mark, A.L., and Haynes, W.G. 2005. Role of selective leptin resistance in diet-induced obesity hypertension. Diabetes. 54:2012-2018.

33. Flier,J.S. 2004. Obesity wars: molecular progress confronts an expanding epidemic. Cell. 116:337-350.
34. Moore, S.J., et al. 2005. Clinical and genetic epidemiology of Bardet-Biedl syndrome in Newfoundland: a 22-year prospective, population-based, cohort study. Am. J. Med. Genet. A. 132:352-360.

35. Grace, C., et al. 2003. Energy metabolism in Bardet-Biedl syndrome. Int. J. Obes. Relat. Metab. Disord. 27:1319-1324.

36. Ryan, M.J., McLemore, G.R., Jr. and Hendrix, S.T. 2006. Insulin resistance and obesity in a mouse model of systemic lupus erythematosus. Hypertension. 48:988-993.

37. Hanada, R., et al. 2004. Neuromedin U has a novel anorexigenic effect independent of the leptin signaling pathway. Nat. Med. 10:1067-1073.

38. Stepanyan, Z., et al. 2003. Leptin-target neurones of the rat hypothalamus express somatostatin receptors. J. Neuroendocrinol. 15:822-830.

39. Baly, C., et al. 2007. Leptin and its receptors are present in the rat olfactory mucosa and modulated by the nutritional status. Brain Res. 1129:130-141.

40. Yen, H.J., et al. 2006. Bardet-Biedl syndrome genes are important in retrograde intracellular trafficking and Kupffer's vesicle cilia function. Hum. Mol. Genet. 15:667-677.

41. Rahmouni, K., Haynes, W.G., Morgan, D.A., and Mark, A.L. 2003. Role of melanocortin-4 receptors in mediating renal sympathoactivation to leptin and insulin. J. Neurosci. 23:5998-6004.

42. DiBona, G.F., and Kopp, U.C. 1997. Neural control of renal function. Physiol. Rev. 77:75-197.

43. Barnes, M.J., et al. 2003. High fat feeding is associated with increased blood pressure, sympathetic nerve activity and hypothalamic mu opioid receptors. Brain Res. Bull. 61:511-519.

44. Kassab, S., et al. 1995. Renal denervation attenuates the sodium retention and hypertension associated with obesity. Hypertension. 25:893-897.

45. Nachury, M.V., et al. 2007. A core complex of BBS proteins cooperates with the GTPase Rab8 to promote ciliary membrane biogenesis. Cell. 129:1201-1213.

46. Weiss, R.M., Ohashi, M., Miller, J.D., Young, S.G., and Heistad, D.D. 2006. Calcific aortic valve stenosis in old hypercholesterolemic mice. Circulation. 114:2065-2069. 